determined by follow-up (mean 22 yrs) of 79 children who presented with a diagnosis of optic neuritis (ON) at the Mayo Clinic between 1950 and 1988. The incidence of MS was $13 \%$ by 10 yrs follow-up and $19 \%$ by 20 yrs. Of the patients who developed MS, 7 of $15(47 \%)$ had symptoms within the first year after recovery from ON; one developed MS after 31 years interval. Four had clinical signs of Devic's disease. Bilateral sequential or recurrent ON increased the risk of MS, whereas unilateral ON was associated with a low risk of MS. Of 37 children with unilateral ON, only $2(5 \%)$ developed MS. The presence of recent infection within 2 weeks of onset of ON decreased the risk of MS. Childhood onset $\mathrm{ON}$ had a lower risk of progression to MS compared to ON in adults. (Lucchinetti CF, Kiers L, O'Duffy A, et al. Risk factors for developing multiple sclerosis after childhood optic neuritis. Neurology Nov 1997;49:1413-1418). (Reprints: Dr M Rodriguez, Department of Neurology, 200 First Street SW, Rochester, MN 55905).

COMMENT. The risk of developing multiple sclerosis after optic neuritis in childhood is lower than in adult-onset ON and increases with length of follow-up from $13 \%$ after 10 years to $22 \%$ by 30 years. Bilateral ON carries a greater risk of MS, whereas infection preceding the ON lessens the risk of MS.

In a previous report from Gottingen, Germany (Hanefeld FA, 1995), onset or relapse of MS was preceded by a nonspecific infection, usually an URI, in $>50 \%$ cases. Of 8 presenting with ON, 4 developed MS within 2 years. (See Progress in Pediatric Neurology III, PNB Publ, 1997;551-554, for further articles on childhood MS).

\title{
CHRONIC INFLAMMATORY POLYRADICULONEUROPATHY
}

The long-term clinical course of 12 children with idiopathic chronic inflammatory demyelinating polyradiculoneuropathy (CIDP) is reported from the University of Michigan, Ann Arbor, and Pennsylvania State University/Hershey Medical Center, Hershey, PA. Data on 62 adults with CIDP previously reported from these centers were used for comparison. In children aged 3 to 17 years, boys and girls were equally affected. Illness duration was 1 to 25 years. In contrast to adults with CIDP, children were more likely to relapse but none was progressive; $83 \%$ childhood cases relapsed cf to $35 \%$ adults. All were treated with prednisone, plasma exchange, or IV immunoglobulin, and recovery from each relapse was excellent. Only 2 with precipitous onset required ventilatory support. Adults showed a more variable outcome. (Simmons Z, Wald JJ, Albers JW. Chronic inflammatory demyelinating polyradiculoneuropathy in children: II. Long-term follow-up, with comparison to adults. Muscle \& Nerve December 1997;20:1569-1575). (Respond: Dr Zachary Simmons, Division of Neurology, Pennsylvania State University College of Medicine, Hershey Medical Center, Hershey, PA 17033).

COMMENT. According to the above study, the long-term prognosis for children with CIDP is excellent, but relapses are to be expected. Those with a slowly progressive onset have a similar outcome to the acute onset cases, and none develops a severe disability. A gradual weaning from therapy is often successful. These findings are in contrast to the experience at Washington University, St Louis, MO, and the Royal Children's Hospital, Melbourne, Australia, as reviewed in Ped Neur Briefs Aug 1996 (Progress in Pediatric Neurology III, 1997;pp360-362). Nevo, Pestronk et al reported that childhood onset CIDP has in general a poor prognosis, the majority relapsing and having residual weakness, and attempts to withdraw steroids frequently unsuccessful. 
Furthermore, these authors distinguished two subtypes of CIDP: 1) with acute or subacute onset, a monophasic course, and complete recovery; and 2) a gradual onset, evolution of symptoms from 3 months to years, residual weakness, and no complete recoveries. Cases with an antecedent URI or tonsillitis recovered completely, whereas cases following MMR immunization had severe residual weakness.

\section{$\underline{\text { TOXIC DISORDERS }}$}

\section{PRENATAL METHYLMERCURY AND COGNITIVE DEFICIT}

A cohort of 1022 consecutive singleton births during 1986-87 in the Faroe Islands, born to mothers who had consumed methylmercury-polluted pilot whale meat and having increased mercury concentrations in cord blood and maternal hair, received neurobehavioral evaluations at 7 years of age at Odense University, Denmark. Deficits in language, attention, and memory, and to a lesser extent in visuospatial and motor functions were revealed, even in children born to mothers with hair mercury concentrations below $10 \mathrm{mcg} / \mathrm{g}$ (50 nmol/g). A doubling in mercury exposure was associated with a developmental delay of 2 months. (Grandjean P, Weihe P, White RF et al. Cognitive deficit in 7-year-old children with prenatal exposure to methylmercury. Neurotoxicol Teratol Nov/Dec 1997;19:417-428). (Reprints: Dr Philippe Grandjean, Odense University, Winslowparken 17, 5000 Odense, Denmark).

COMMENT. Neurobehavioral dysfunction in children born in the Faroe Islands can be related to prenatal methylmercury exposure, and has been detected at exposure levels currently considered safe.

The neurological long-term effects of methylmercury poisoning were described in three children and a neonate in a New Mexico family who had consumed pork containing methylmercury. (Davis LE et al. 1994. Reviewed in Progress in Pediatric Neurology III, 1997;p279). At 22 year follow-up, 2 had died, and 2 had cortical blindness, ataxia, and attentional deficits.

\section{LEARNING AND BEHAVIOR DISORDERS}

\section{ASPERGER'S DISORDER AND TOURETTE SYNDROME}

Five boys with both Asperger's disorder and Tourette syndrome, exceptional verbal intelligence, and clumsiness presented with peer-related social difficulties and a flapping stereotypy in a report from New York University Medical Center. Highly specialized interests - computers, chess, music - were characteristic. Speech was sing-song or mechanical, with poor pitch modulation, conversation overfocused or tangential, and eye contact poor. Neurologic exam revealed soft signs involving incoordination of tandem gait, finger tapping, and eye-hand clumsiness. WISC IQ showed very superior verbal scores (mean, 140) and lower performance scores (mean, 115). Despite the high IQ academic performance was poor. Visuoperceptual, motor, and attentional impairments were noted. Tics exacerbated social difficulties. (Nass R, Gutman R. Boys with Asperger's disorder, exceptional verbal intelligence, tics, and clumsiness. Dev Med Child Neurol Oct 1997;39:691-695). (Respond: Dr Ruth Nass, NYU Medical Center, 400 East 34 Street, RR311, New York, NY 10016).

COMMENT. Asperger's disorder should be considered in children of high verbal intelligence who do poorly in school, both academically and socially, 